\title{
Tip 1 Diyabetli Çocuk ve Adolesanlarda Kardiyak Fonksiyonların Konvansiyonel Ekokardiyografi ile Erken Dönem Değerlendirilmesi
}

\author{
Early Evaluation of Cardiac Functions by Conventional Echocardiography in Children \\ and Adolescents with Type 1 Diabetes
}

\section{Nilüfer ÇETİNER ${ }^{1}$, Semih BOLU ${ }^{2}$, Habip ALMIŞ ${ }^{3}$, Fatih IŞLEYEN ${ }^{4}$, Mehmet TURGUT ${ }^{5}$}

1. Koç Üniversitesi Tıp Fakültesi, Pediatrik Kardiyoloji Bilim Dalı, İstanbul, Türkiye

2. Adıyaman Üniversitesi Tıp Fakültesi, Pediyatrik Endokrinoloji Bilim Dalı, Adıyaman, Türkiye

3. Adıyaman Üniversitesi Tıp Fakültesi, Pediyatri Anabilim Dalı, Adıyaman, Türkiye

4. Adıyaman Üniversitesi Tıp Fakültesi, Pediyatik Enfeksiyon Hastalıkları Bilim Dalı, Adıyaman, Türkiye

\section{$\ddot{O Z Z E T}$}

Amaç: Kardiyak disfonksiyonun tip 1 diyabetin ciddi ve s1k görülen komplikasyonlarından biri olduğu bilinmektedir. Bu çalıșmanın amacı, tip 1 diyabet tanılı çocuk ve adolesanların kardiyak etkilenmenin konvansiyonel ekokardiyografi ile erken dönemde değerlendirilmesiydi.

Gereçler ve Yöntem: Çalışmada 53 tip 1 Diyabet tanılı çocuk ve adolesan ile benzer yaș ve cinsiyette 55 sağlıklı çocuk ve adolesan yer almaktadır. Katılımcıların, boy, kilo, vücut kitle indeksi ve kan basıncı değerleri kaydedildi. Tip 1 diyabetli hasta grubunda glisemik kontrol için glikolize hemoglobin ölçümü yapıldı. Tüm katılımcıların miyokardiyal sistolik ve diyastolik fonksiyonları konvansiyonel ekokardiyografi yöntemi ile değerlendirildi.

Bulgular: Tip 1 diyabetli 53 hastada kontrol grubuna göre triküspid kapağın A dalga akım hızı anlamlı yüksek $(\mathrm{p}=0,04)$ ve triküspid $\mathrm{E} / \mathrm{A}$ oranı ise anlamlı düşük $(\mathrm{p}=0,02)$ bulundu. Sol ventrikül fraksiyonel kısalma ve ejeksiyon fraksiyonu hasta grubunda kontrole göre daha düşük bulundu, ancak istatikse olarak anlamlı değildi ( $\mathrm{p}$ değerleri sırasıyla $0,675,0,933$ ). Hasta grubunda glikolize hemoglobin düzeyi ile sol ventrikül sistolik fonksiyonu arasında ise istatiksel olarak anlamlı negatif korelasyon bulundu $(\mathrm{p}=0,049, \mathrm{r}=-0,669)$.

Sonuç: Tip 1 diyabet tanısı olan çocuk ve adolesanlarda erken dönemde bile ekokardiyografik olarak sağ ventrikülde diyastolik disfonksiyon ve glikolize hemoglobin düzeyi ile sol ventrikül ejeksiyon fraksiyonu arasında negatif korelasyonun gösterilmesi, kötü glisemik kontrollü diyabetik hastaların peryodik olarak kardiyak değerlendirmelerinin noninvazif tanı yöntemi olan ekokardiyografi ile yapılmasının gerekli olduğunu düşündürmektedir.

Anahtar Kelimeler: adolesan, çocuk, ekokardiyografi, kardiyak disfonksiyon, tip 1 diyabet

\section{ABSTRACT}

Objective: It is known that cardiac dysfunction is one of the serious and common complications of type 1 diabetes. The aim of this study was to evaluation early cardiac functions of children and adolescents with type 1 diabetes by conventional echocardiography.

Material and Methods: This study included 53 children and adolescents with type 1 diabetes and 55 age-sex matched İletișim

Sorumlu Yazar: Nilüfer ÇETINER

Adres: Maltepe Mah. 324 Sk., Beyaz Rezidans-2, B-Blok D: 12 Zeytinburnu, İstanbul, Türkiye

Tel: +90 (505) 8326343

E-Posta: nilufercetiner@hotmail.com

Makale Gelis: 10.10.2019

Makale Kabul: 07.02.2020

DOI: http://dx.doi.org/10.16948/zktipb.631740 healty children and adolescents. The values of height, weight, body-mass index and blood pressure of the all participants were recorded. Glycated hemoglobin measuring was performed for glycemic control in patients with type 1 diabetes. Myocardial systolic and diastolic functions of all paticipants were assessed by conventional echocardiography.

Results: A wave velocity of tricuspid valve was significantly higher $(\mathrm{p}=0,04)$ and tricuspid $\mathrm{E} / \mathrm{A}$ rate was significantly less $(p=0,02)$ in patients with type 1 diabetes than controls. Fractional shortening and ejection fraction of left ventricular revealed less in the patient groups than controls, but they were no statistically significant differences ( $p$ values $0,675,0,933$ respectively). Statistically significant negative correlation was noted between level of glycated hemoglobin and ejection fraction of left ventricular in patients group $(p=0,049, r=-0,669)$.

Conclusion: Determination of right ventricular diastolic dysfunction and negative corrrelation between level of glycated hemoglobin and left ventricular ejection fraction in children and adolescents with type 1 diabetes suggest, that cardiac evaluation of poor glycemic controlled diabetic patients is necessary periodically performing by echocardiography, which is noninvasive diagnostic method.

Keywords: adolescent, child, echocardiography, cardiac dysfunction, type 1 diabetes

\section{GÍRIŞ}

Tip 1 diyabet, çocukluk çağında sık görülen endokrin ve metabolik durumlardan biridir [1]. Klinik ve deneysel olarak yapılan birçok çalışmada, koroner arter hastalığ 1 ve hipertansiyona bağlı olmadan gelişen diyabetik kardiyomiyopatinin kanıtları gösterilmiştir [2, 3]. Diyabetik kardiyomiyopati, genellikle erişkinlerde görülmekte ve sistolik, diyastolik veya her iki fonksiyonu da etkileyebilmektedir [4, 5]. Benzer şekilde adolesan ve çocuklarda da sol ventrikül çap ve miyokardiyal gevșemede değișiklikler gösterilmiștir. Yapılan çalıșmalarda, sürecin erken çocukluk çağında başladığ 1 ve sistolik-diyastolik disfonksiyonun, özellikle hastalık süresi ve kötü glisemik kontrolle ilişkili olduğu gösterilmiştir [6-8].

Ekokardiyografi, diyabetin sebep olduğu miyokardiyal disfonksiyonu göstermede kullanılan non-invazif ve kolay ulaşılabilir bir görüntüleme yöntemidir. Konvensiyonel ekokardiyografi, diyabete sekonder gelişen kardiyak etkilenmeyi erken dönem ve progresyonunu belirlemede etkin bir yöntem olarak kabul edilmektedir $[9,10]$.

$\mathrm{Bu}$ çalışmadaki amaç, konvensiyonel ekokar- 
diyografi ile Tip 1 diyabet tanılı çocuk ve adolesanlarda erken dönemdeki miyokardiyal etkilenmeyi ve bu etkilenmenin glisemik kontrolle olan ilişkisini göstermektir.

\section{GEREÇ ve YÖNTEM}

\section{Çalıșma Grubu}

Çalışma, 2015-2017 yılları arasında hastanemiz çocuk endokrinoloji polikliniğinden Tip 1 diyabet tanısı ile izlenmekte olan ve randomize olarak seçilen, yaşları 3-17 arasında değişen 53 çocuk ve adolesan ile yaş-cinsiyet uyumu olan, daha önce bilinen kronik hastalığı olmayan 55 sağlıklı çocuk ve adolesan dahil edilmiştir. Tip 1 diyabetli hasta grubunda, ek kronik hastalığı, obezitesi ve diyabete sekonder gelişen retinal, renal veya nörolojik hastalık gibi majör komplikasyonları olanlar çalışma dışı bırakılmıştır. Her iki gruptaki çocukların boy, kilo ölçümleri alındı, vücut-kitle endeksleri hesaplandı ve kan basıç̧ları standart civalı manometre ile ölçüldü. Sistolik ve diyastolik kan basınçları kaydedildi. Katılımcıların tüm sistemik muayeneleri yapild.

Hasta grubunun glikolize hemoglobin A1c (HbA1c) düzeyleri ölçüldü ve düzeyi $\% 8,5$ üzerinde olanlar kötü kontrollü olarak kabul edildi. Çalışmaya dahil edilen katılımcıların velisinden yazılı ve sözlü onam alındı. Ayrıca hastanemiz etik kurulundan onay alındı.

\section{Konvansiyonel Ekokardiyografi}

Hasta ve kontrol grubuna ekokardiyografi, tek bir araştırmacı tarafından General Electric (GE Vivid S6 Horten, Norway) standart ultrason cihaz1 kullanılarak 5 ve $8 \mathrm{MHz}$ problar ile eş zamanlı elektrokardiyogram (standart derivasyon II) eşliğinde yapild1. 2-boyutlu ekokardiyografide, standart sol ventrikül çap ve fonksiyonları M-mod kayıtla elde edildi. M-mod ekokardiyogram, "American Society of Echocardiography" önerileri göz önüne alınarak en az üç kardiyak siklus ortalaması alınarak analiz edildi. Ölçümler, (a) sol ventrikül enddiyastolik çap (LVEDD) ve endsistolik çap (LVESD); (b) interventriküler (IVS) ve arka duvar kalınlığı (LVPWD) idi. Fraksiyonel kısalma (FS) FS= (LVEDD-LVESD)/ LVEDDx $100 \%$ formülü; ve ejeksiyon fraksiyonu (EF) $\mathrm{EF}=($ LVEDD3 -LVESD3)/LVEDD3 formülü kullanılarak hesaplandı. Eğer LVEF $>\% 55$ ve FS $>\% 28$ ise, sistolik fonksiyon normal olarak kabul edildi [11].

Mitral ve triküspid kapak akımının konvansiyonel doppler ölçümleri (pulse wave Doppler), apikal dört-boşluk görüntüden elde edildi. Doppler kürsör çizgisi, akıma paralel açıyla inlete yerleştirildi. Transmitral Doppler akım hızı sinyalleri, en az 3 kardiyak siklus ortalamasıyla elde edildi. Bunlar, (a) erken sol ventrikül diyastolik dolum boyunca pik akım hızı (E dalgası); (b) geç sol ventrikül diyastolik dolum pik akım hızı (A dalgası); (c) pik akım hızı oranı (E/A). Ayrıca deselerasyon zamanı (DT) ve izovolumik gevşeme zamanı (IVRT) belirlendi. Erken sağ ventrikül dolum (E dalgasi) ve geç sağ ventrikül dolum (A dalgası) ve E/A oranı transtriküspid Doppler ile belirlendi [12]. Diyasto- lik fonksiyonlar aşağıdaki gibi yorumlandı:

1. Normal diyastolik fonksiyon $(\mathrm{E}>\mathrm{A})$

2. Bozulmuş Gevşeme (E:A ters, $\mathrm{E}<\mathrm{A}$ )

3. Pseudonormal (E:A oranı normal görülmekte)

4. Restriktif dolum (E:A oranı $>2)$

\section{İstatiksel Analiz}

Çalışmada elde edilen bulgular değerlendirilirken, istatistiksel analizler için SPSS (statistical package for social sciences) version 22 program1 kullanıldı. Çalışma verileri değerlendirilirken tanımlayıcı istatistiksel metodların (Ortalama, Standart sapma, frekans) yanısira niteliksel verilerin karş1laştırılmasında ise Ki-Kare testi ve Anova testi kullanıldı. Sonuçlar \%95'lik güven aralığında, anlamlılık $\mathrm{p}<0.05$ düzeyinde değerlendirildi.

\section{BULGULAR}

Çalışma, 53 tip 1 diyabet tanılı hasta çocuk ve adolesan ile 55 kontrol grubundan oluşmaktadır. Tip 1 diyabetli grubun 23'ü k1z, 30'u erkek, kontrol grubunun 23'ü kız ve 32'i erkekti. Hastaların yaşlar1 3-17 y1l (ort $\pm \mathrm{SD}=9,2 \pm 3,4$ ) ve kontrol grubunun yaşları ise 4-17 yıl (ort $\pm \mathrm{SD}=9,5 \pm 3,1$ ) arasındaydı. Her iki grup yaş, cinsiyet, boy-kilo, BMI ve sistolik ve diyastolik kan basıncı açısından karşılaştırıldı (Tablo 1). Tip 1 diyabetli olma süresi $541 \pm 381,25$ gündü ve ortalama glikolize hemoglobin değeri \% $12,05 \pm 2,85$ ve hastalardan 14 'ünde düzey $\% 8,5$ altında idi. Tüm hastalar insülin tedavisi almaktaydı.

Tablo 1: Hasta ve Kontrol Grubunun Demografik ve Laboratuvar Özellikleri.

\begin{tabular}{|l|l|l|l|}
\hline & \multicolumn{1}{|c|}{$\begin{array}{c}\text { Hasta } \\
\text { Ort } \pm \text { SD }\end{array}$} & $\begin{array}{c}\text { Kontrol } \\
\text { Ort } \pm \text { SD }\end{array}$ & $\begin{array}{c}\text { p } \\
\text { değeri }\end{array}$ \\
\hline Yaş (yıl) & $9,2 \pm 3,4$ & $9,5 \pm 3,1$ & 0,64 \\
\hline Cinsiyet $(\mathrm{K} / \mathrm{E})$ & $23 / 30$ & $23 / 32$ & \\
\hline Boy $(\mathrm{cm})$ & $139,09 \pm 22,7$ & $133,84 \pm 19,07$ & 0,05 \\
\hline Ağırlı $(\mathrm{kg})$ & $39,51 \pm 16,15$ & $32,91 \pm 13,51$ & 0,07 \\
\hline BMI $\left(\mathrm{kg} / \mathrm{m}^{2}\right)$ & $17,47 \pm 2,51$ & $17,47 \pm 2,80$ & 0,92 \\
\hline SKB $(\mathrm{mmHg})$ & $103,5 \pm 8,7$ & $101,2 \pm 5,8$ & 0,06 \\
\hline DKB $(\mathrm{mmHg})$ & $62,6 \pm 7,5$ & $60,8 \pm 6,6$ & 0,07 \\
\hline HbA1c $(\%)$ & $12,05 \pm 2,85$ & & \\
\hline Diyabet süresi (gün) & $541 \pm 381,25$ & & \\
\hline
\end{tabular}

BMI: Body-mass index, SKB: sistolik kan basınc1, DKB: diyastolik kan basinc1

Her iki grubun ekokardiyografik M-mod ölçümleri, sol ve sağ ventrikül diyastolik fonksiyonları karşılaştırıldı (Tablo 2-3).

Tablo 2: M-Mod Ekokardiyografi Verilerinin Hasta ve Kontrol Grubunda Karşılaştırılması.

\begin{tabular}{|l|l|l|l|}
\hline & \multicolumn{1}{|c|}{$\begin{array}{c}\text { Hasta } \\
\text { Ort } \pm \text { SD }\end{array}$} & \multicolumn{1}{|c|}{$\begin{array}{c}\text { Kontrol } \\
\text { Ort } \pm \text { SD }\end{array}$} & $\begin{array}{c}\text { p } \\
\text { değeri }\end{array}$ \\
\hline AO $(\mathrm{mm})$ & $22,50 \pm 2,75$ & $21,20 \pm 3,10$ & 0,06 \\
\hline LA $(\mathrm{mm})$ & $23,80 \pm 3,11$ & $23,33 \pm 3,28$ & 0,79 \\
\hline LVEDd $(\mathrm{mm})$ & $37,25 \pm 6,08$ & $36,91 \pm 5,80$ & 0,77 \\
\hline LVEDs $(\mathrm{mm})$ & $23,39 \pm 4,04$ & $23,23 \pm 2,90$ & 0,84 \\
\hline IVSD $(\mathrm{mm})$ & $6,75 \pm 1,41$ & $6,53 \pm 0,83$ & 0,216 \\
\hline LVPWD $(\mathrm{mm})$ & $7,04 \pm 1,00$ & $6,92 \pm 0,91$ & 0,51 \\
\hline FS $(\%)$ & $37,52 \pm 3,07$ & $37,76 \pm 2,72$ & 0,675 \\
\hline EF $(\%)$ & $68,00 \pm 3,63$ & $68,54 \pm 3,52$ & 0,933 \\
\hline
\end{tabular}

AO: aort, LA: sol atriyum, LVEDd: sol ventrikül enddiyastolik çap, LVEDs: sol ventrikül endsistolik çap, IVSD: interventriküler septum kalınlığı, LVPWD: sol ventrikül arka duvar kalınlığı, FS: kısalma fraksiyonu, EF: ejeksiyon fraksiyonu 
Tablo 3: Pulse Wave Ekokardiyografik Verilerin Hasta ve Kontrol Grubuyla Karşılaştırılması.

\begin{tabular}{|c|c|c|c|}
\hline & $\begin{array}{c}\text { Hasta } \\
\text { Ort } \pm \text { SD }\end{array}$ & $\begin{array}{l}\text { Kontrol } \\
\text { Ort } \pm \text { SD }\end{array}$ & $\begin{array}{c}\mathrm{p} \\
\text { değeri }\end{array}$ \\
\hline Triküspid E (m/sn) & $0,67 \pm 0,08$ & $0,69 \pm 0,09$ & 0,17 \\
\hline Triküspid A (m/sn) & $0,54 \pm 0,10$ & $0,51 \pm 0,10$ & 0,04 \\
\hline E/A oranı (triküspid) & $1,25 \pm 0,19$ & $1,38 \pm 0,23$ & 0,02 \\
\hline Mitral E (m/sn) & $0,96 \pm 0,12$ & $0,99 \pm 0,14$ & 0,36 \\
\hline Mitral A (m/sn) & $0,55 \pm 0,11$ & $0,56 \pm 0,12$ & 0,16 \\
\hline E/A oranı (mitral) & $1,78 \pm 0,36$ & $1,79 \pm 0,35$ & 0,14 \\
\hline DT mitral (msn) & $133,19 \pm 25,83$ & $137,67 \pm 32,10$ & 0,10 \\
\hline IVRT mitral (msn) & $54,43 \pm 5,20$ & $55,34 \pm 7,24$ & 0,71 \\
\hline
\end{tabular}

DT: deselerasyon zamanı, IVRT:izovolumetrik relaksasyon zamanı

Aort (Ao), sol atriyum (LA), interventriküler septum (IVS), sol ventrikül arka duvar (LVPWD), sol ventrikül enddiyastolik (LVEDD) ve endsistolik (LVESD) çapları hasta grubunda kontrol grubuna göre yüksekti, ancak istatiksel olarak anlamlı değildi (p değerleri sırasıyla 0,06, 0,79, 0,77, 0,84, 0,216, $0,51,0,675,0,933)$. Fraksiyonel kisalma (FS) ve ejeksiyon fraksiyonu (EF) hasta grubunda kontrole göre düşük bulundu, ancak istatiksel olarak anlamlı değildi (p değerleri sirasıyla 0,675, 0,933). Doppler ekokardiyografik çalıșmada, mitral kapağın E dalga akım hız1, DT ve IVRT süreleri hasta grubunda kontrol grubuna göre azalmış bulundu, ancak istatiksel olarak anlamlı değildi. Triküspid kapağın A dalga akım hızı hasta grubunda kontrole göre yüksek ve E/A oranı ise kontrole göre düşük bulundu ve bulgular istatiksel olarak anlamlı saptandı (p değerleri sirasiyla 0,04, 0,02).

\section{Korelasyon Analizi}

Tip 1 diyabetli hasta grubu içerisinde, ortalama $\mathrm{HbA} 1 \mathrm{c}$ düzeyi ile sol ventrikül M-mod ölçümleri ve sol-sağ ventrikül diyastolik fonksiyonları arasında korelasyon analizi yapıldı. HbA1c düzeyi ile sol ventrikül ejeksiyon fraksiyonu arasinda istatiksel olarak anlamlı negatif korelasyon bulundu, ancak diyabetli olma süresi ve diğer parametreler ile istatiksel olarak anlamlı korelasyon saptanmadı (Şekil 1).

Şekil 1: HbA1c değerleri ile Sol Ventrikül Ejeksiyon Fraksiyonu Arasindaki Korelasyon.

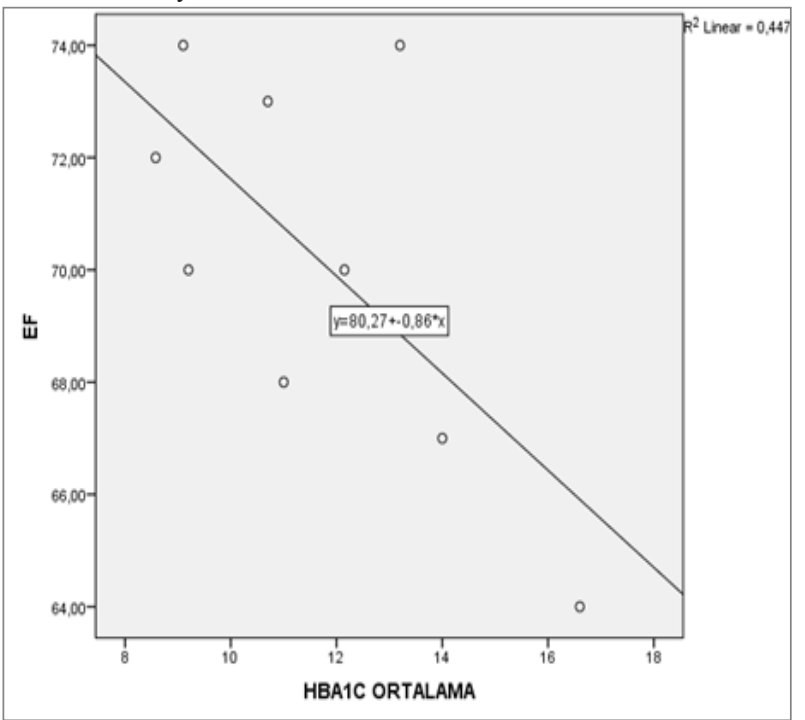

\section{TARTIŞMA}

Tip 1 diyabetli hastalarda görülen diyabetik kardiyomiyopati, miyokardiyal dilatasyon ve sol ventrikül sistolik ve diyastolik fonksiyonlarda azalma ile karakterize kardiyak hasarlanma olarak tanımlanmaktadır [12]. Literatürde, diyabetik kardiyomiyopatinin ilk aşamasının ventrikül diyastolik disfonksiyonun olduğu görüşü yaygındır $[13,14]$. $\mathrm{Bu}$ çalışmadaki ana bulgumuz literatürü destekler nitelikte olup, tip 1 diyabet tanılı çocuk ve adolesanlarda her iki ventrikül diyastolik fonksiyonlarındaki azalmayla ilişkili olan mitral ve triküspid kapak anuluslarından ölçülen düşük E/A oranlar1 olmuştur. Daha önce yapılan bazı çalışmalarda, ventrikül diyastolik disfonksiyonun yüksek vücut kitle indeksi ile ilişkilendirilmiş ve yüksek BMI'in azalmış diyastolik fonksiyon için risk faktörü olduğu belirtilmiş [15]. Bir başka çalışmada ise, cinsiyetler arasında anlamlı farklılık bulunmuştur[(16]. Bu çalışmada ise, diyastolik fonksiyonlarda azalma ile cinsiyet ve BMI değerleri arasında anlamlı bir korelasyon izlenmedi. Çalışmamızdaki bu bulgu, diyabetli çocuk ve adolesanlarda fazla kilolu çocukların az sayıda yer alması ve obez çocukların çalışma dışı bırakılmasıyla ilişkilendirilebilir.

$\mathrm{Bu}$ çalışmada, E/A oranı ile diyabetli olma süresi ve HbA1c düzeyleri arasında diğer yapılan çalıșmaların aksine anlamlı bir ilișki bulunmadı. Bizim çalışmamızdaki bu bulgu, hasta grubundaki katılımcıların genç yaşta olması ve diyabetli olma süresinin nispeten daha kısa olmasıyla ilişkilendirilebilir. Ancak çalışmamızda HbA1c düzeyi ile sol ventrikül sistolik fonksiyonunu gösteren ejeksiyon fraksiyonu arasinda negatif bir korelasyon bulundu. Bu bulgu, literatürde kötü glisemik kontrolün sistolik ve diyastolik disfonksiyon için bir risk faktörü olduğu yönündeki görüșünü desteklemektedir [17-19]. Kabul edilen görüşe göre hipergliseminin kalp üzerine olan etkisi, kalp metabolizmasını glikozilasyon son ürünleri, oksidatif stres ve protein kinaz $\mathrm{C}$ aktivasyonu yoluyla etkilemesidir. $\mathrm{Bu}$ süreç, hipergliseminin sürekli olması durumunda kardiak disfonksiyon gelișimine zemin hazırlamaktadır [20]. İyi glisemik kontrollü Tip 1 diyabetli çocuk ve adolesanlarda yapılan bir çalışmada dahi sol ventrikül diyastolik fonksiyonlarında azalma olduğu bulunmuştur [21]. Asemptomatik olan tip 1 diyabetli çocuklarda yapılan bazı çalışmalarda, subklinik olarak sol ventrikül sistolik fonksiyonunun göstergesi olan EF değerinde anlamlı azalma olduğu gösterilmiştir. Bazı çalışmalarda ise, asemptomatik tip 1 diyabetli çocuk ve adolesanlarda sol ventrikül EF normal olmasına rağmen global sol ventrikül longitudinal strain değerlerinde anlamlı düşüş olduğu saptanmıştır [22-24].

Yapılan birçok çalışmada, tip 1 diyabetli çocuk ve adolesanlarda diyabet süresiyle LV enddiyastolik çap genişliği ilişkilendirilmiştir. Uzun hastalık süresi ve kötü glisemik kontrolün sol ventrikül dilatasyonuna ve sonrasında disfonksiyonuna yol açtığ 1 görüşü öne sürülmüştür [9]. Bu çalışmada da, hasta grubundaki çocuk ve adolesanlarda LV enddiyastolik ve endsistolik çaplar kontrol grubuna göre artmış bulundu, ancak istatiksel olarak anlamlı değildi. 
$\mathrm{Bu}$ çalışmadaki bulgumuz, katılımcıların diyabetli olma süresinin nispeten kısa olması ile ilişkilendirilebilir.

$\mathrm{Bu}$ çalışma ile, tip 1 diyabet tanısı olan ve insülin tedavisi alan çocuk ve adolesanlarda, uzun hastalık süresi olmasa dahi ekokardiyografik olarak sağ ventrikül diyastolik fonksiyonlarında azalmanın olduğu ve bu hastalarda kötü glisemik kontrolün sol ventrikül sistolik fonksiyonunu olumsuz yönde etkilediği gösterilmiştir. Bu bulgulara dayanarak, asemptomatik tip 1 diyabetli çocuk ve adolesanlarda erken dönemdeki kardiyak etkilenmeyi göstermede, kolay erişilebilir ve iyi bir tanı aracı olan ekokardiyografinin yararlı olabileceği ve kötü glisemik kontrolün bir risk faktörü olduğu vurgulanmak istenmiştir.

\section{KAYNAKLAR}

1. International Diabetes Federation. IDF Diabetes Atlas, 5th ed. Brussels: International Diabetes Federation; 2011.

2. Hill MF. Diabetic cardiomyopathy: Cardiac changes. Pathophysiological mechanisms. Biologic markers and the available therapeutic armamentarium. In: Cardiomyopathies - from basic research to clinical management. Veselka J (Ed) 2012:487-512.

3. Feuvray D. Cardiac metabolism in the diabetic patient. Heart Metab. 2010;46:11-5.

4. Kiencke S, Handschin R, von Dahlen R, Muser J, Brunner-LaRocca HP, Schumann J, et al. Pre-clinical diabetic cardiomyopathy: prevalence, screening, and outcome. Eur J Heart Fail. 2010;12(9):951-7.

5. From AM, Scott CG, Chen HH. The development of heart failure in patients with diabetes mellitus and pre-clinical diastolic dysfunction a populationbased study. J Am Coll Cardiol. 2010;55(4):300-5.

6. Jensen MT, Sogaard P, Andersen HU, Bech J, Hansen TF, Biering Soerensen T, et al. Prevalence of systolic and diastolic dysfunction in patients with type 1 diabetes without known heart disease: the Thousand \& 1 Study. Diabetologia. 2014;57(4):672-80.

7. Karamitsos TD, Karvounis HI, Dalamanga EG, Papadopoulos CE, Didangellos TP, Karamitsos DT, et al. Early diastolic impairment of diabetic heart: The significance of right ventricle. Int J Cardiol. 2007;114(2):218-23.

8. Vazeou A, Papadopoulou A, Miha M. Cardiovascular impairment in children, adolescents, and young adults with type 1 diabetes mellitus (T1DM). Eur J Pediatr. 2008;167:877-84.

9. Kim EH, Kim YH. Left ventricular function in children and adolescents with type 1 diabetes mellitus. Korean Circ J 2010;40(3):125-30.

10. Elshahed GS, Ahmed MI, El-Beblawy NS, Kamal HM, Ismaiel MF, Bin Zheidan OAS. Evaluation of right and left ventricular systolic and diastolic function in patients with type 1 diabetes using echocardiography and tissue Doppler imaging. Suez Canal Univ Med J 2008;11:65-74.

11. Lang RM, Bierig M, Devereux RB, Flachskampf FA, Foster E, Pellikka PA, et al: Recommendations for chamber quantification: A report from the American Society of Echocardiography's Guidelines and Standards Committee and the Chamber Quantification Writing Group, developed in conjunction with the European Association of Echocardiography, a branch of the European Society of Cardiology. J Am Soc Echocardiogr 2005;18(12):1440-63.

12. Voulgari C, Papadogiannis D, Tentolouris N. Diabetic cardiomyopathy: from the pathophysiology of the cardiac myocytes to current diagnosis and management strategies. Vasc Health Risk Manag 2010;6:883-903.

13. Khattab AA, Soliman MA: Biventricular function and glycemic load in type 1 diabetic children: Doppler tissue-imaging study. Pediatr Cardiol 2015;36:423-31.

14. Asghar O, Al-Sunni A, Khavandi K, et al: Diabetic cardiomyopathy. Clin Sci (Lond) 2009;116(10):741-60.

15. Brunvand L, Fugelseth D, Stensaeth KH, Dahl-Jørgensen K, Margeirsdottir HD. Early reduced myocardial diastolic function in children and adolescents with type 1 diabetes mellitus a population-based study. BMC Cardiovasc Disord.2016; (25);16:103.

16. Suys BE, Katier N, Rooman RP, Matthys D, Op De Beeck L, Du Caju MV, et al. Female children and adolescents with type 1 diabetes have more pronounced early echocardiographic signs of diabetic cardiomyopathy. Diabetes Care. 2004;27(8):1947-53.

17. Aepfelbacher FC, Yeon SB, Weinrauch LA, D'Elia J, Burger AJ. Improved glycemic control induces regression of left ventricular mass in patients with type 1 diabetes mellitus. Int J Cardiol. 2004;94:47-51.

18. Shivalkar B, Dhondt D, Gaal LV, Bartunek J, Crombrugge PV, Vrints C. Flow mediated dilatation and cardiac function in type 1 diabetes mellitus. Am J Cardiol. 2006;97(1):77-82.

19. Abd EI, Dayem SM, Battah AA. Effect of glycaemic control on the progress of left ventricular hypertrophy and diastolic dysfunction in children with type 1 diabetes mellitus. Anadolu Kardiyol Derg. 2012;12:498-507.

20. Van Heerebeek L, Hamdani N, Handoko ML, Falcao-Pires I, Musters RJ, Kupreishvili K, et al. Diastolic stiffness of the failing diabetic heart: importance of fibrosis, advanced glycation end products, and myocyte resting tension. Circulation. 2008;117(1):43-51.

21. Yoldaş T, Örün UA, Sagsak E, Aycan Z, Kaya Ö, Özgür S, Karademir S. Subclinical left ventricular systolic and diastolic dysfunction in type 1 diabetic children and adolescents with good metabolic control. Echocardiography. 2018 Feb;35(2):227-33.

22. Nakai H, Takeuchi M, Nishikage T, Lang RM, Otsuji Y: Subclinical left ventricular dysfunction in asymptomatic diabetic patients assessed by two-dimensional speckle tracking echocardiography: Correlation with diabetic duration. Eur J Echocardiogr 2009;10(8):926- 32.

23. Sanderson JE, Fraser AG: Systolic dysfunction in heart failure with a normal ejection fraction: Echo-Doppler measurements. Prog Cardiovasc Dis 2006;49(3):196-206.

24. Altun G, Babaoğlu K, Binnetoğlu K, Özsu E, Yeşiltepe Mutlu RG, Hatun Ş. Subclinical Left Ventricular Longitudinal and Radial Systolic Dysfunction in Children and Adolescents with Type 1 Diabetes Mellitus. Echocardiography. 2016 Jul;33(7):1032-39. 